\title{
Plataformas y proyectos de crowdsourcing y crowdfunding cinematográfico en España (2007-2011)
}

\author{
Francisco David Martínez Gallardo \\ Universidad de Córdoba \\ z22magaf@uco.es \\ Jordi Alberich Pascual \\ Universidad de Granada \\ jalberich@ugr.es
}

\begin{abstract}
Resumen
El presente artículo analiza la emergencia de iniciativas pioneras de crowdsourcing cinematográfico en España en el quinquenio 2007-2011. Para ello, se exploran en primer lugar los cambios en las industrias creativas vinculados con estrategias de trabajo colaborativo en red. A continuación, realizamos una selección de plataformas pioneras de crowdfunding y de proyectos afines de producción cinematográfica española en el periodo de estudio establecido. Finalmente, ofrecemos las claves e implicaciones industriales y culturales del conjunto de las iniciativas pioneras tratadas.
\end{abstract}

Palabras Clave: Crowdsourcing; Crowdfunding; Producción cinematográfica; Software libre; Cultura colaborativa.

\section{Crowdfunding Platforms and Crowdsourcing Film Projects in Spain (2007-2011)}

\begin{abstract}
This article discusses the emergence of pioneering crowdsourcing in Spanish cinematography in the period 2007-2011. This will first explore the changing that Internet is promoting in creative industries and their links with collaborative networking strategies. After that, we focus our attention on a selection of especific spanish platforms and projects of audiovisual collaborative production in the period of analysis set. Finally, the paper concludes by identifying the cultural and industrial implications of all the most important pioneering initiatives analyzed in the course of our investigation..
\end{abstract}

Key words: Crowdsourcing; Crowdfunding; Film Production; Free Software; Collaboration Culture

\section{Referencia normalizada:}

Martínez Gallardo, F. D. y Alberich Pascual, J. (2013) Plataformas y proyectos de Crowdsourcing y crowdfunding cinematográfico en España (2007-2011). Historia y Comunicación Social. Vol. 18 N $^{\circ}$ Especial Octubre. Págs. 85-95.

Sumario: 1. Introducción. 2. Marco teórico y aspectos metodológicos. 3. La cultura libre en las industrias creativas. 4. Producción colaborativa de proyectos cinematográficos. 5. Plataformas y proyectos de crowdsourcing y crowdfunding en la producción cinematográfica española. 5.1. Plataformas. 5.2. Proyectos. 6. Conclusiones. 7. Referencias bibliográfica 


\section{Introducción}

Internet y el conjunto de los nuevos medios de comunicación digital han posibilitado la irrupción revolucionaria en la escena contemporánea de una cultura de autoproducción y producción colaborativa en red, esto es, la capacidad de desarrollar creaciones y producciones culturales de forma colectiva, anónima y transnacional. Un campo discursivo que se desarrolla además en numerosas ocasiones de forma libre y desinteresada, cuando no directamente altruista.

En relación con el campo cultural descrito, el presente artículo tiene como objetivos tanto la urbanización conceptual como la exploración de las implicaciones que estas nuevas vías de financiación y de producción propias de la sociedad red -de naturaleza eminentemente colaborativa- tienen para el conjunto de las industrias creativas contemporáneas.

Vías, proyectos e iniciativas exponentes todas ellas de una corriente cultural emergente en el seno de la sociedad red contemporánea que establece e impulsa en su devenir modelos innovadores de creación y producción cultural abiertos y participativos, alternativos al modelo precedente -jerárquico y cerrado- propio de los Media tradicionales (Jenkins, 2003; 2006)

\section{Marco teórico y aspectos metodológicos}

La vitalidad tanto de plataformas para la financiación colaborativa de proyectos culturales, como de redes y herramientas participativas para ello resultan hoy un claro exponente de los intensos procesos de cambio y redefinición de roles en las industrias creativas contemporáneas a los cuales estamos asistiendo en la última década, tal y como los estudios precedentes de Hartley (2005, 2008), Hesmondhalgh (2008), o Christopherson (2008) entre otros han evidenciado.

Resultan igualmente cruciales para la necesaria acotación del marco teórico implicado las aportaciones realizadas en relación a la conceptualización y a la promoción de una cultura participativa emergente en pos del dominio público y del bien común digital en autores como Lessig (2004, 2008), Himanen (2001), Stallman (2002) o Raymond (1999) en la escena internacional, así como los trabajos previos en el panorama nacional de Casacuberta (2003), Xalabarder (2006), Alberich \& Roig (2008, 2010), y más recientemente, Estellés Arolas \& Ladrón de Guevara (2012), Martínez García (2012) y Roig et al. (2012) en el ámbito nacional.

Igualmente, hemos considerado substratos discursivos de proyectos e iniciativas significativas afines, a) los antecedentes y fundamentos del movimiento por una cultura libre fijados a través de la Free Software Foundation y la Open Source Initiative, b) los sistemas Copyright versus CopyLeft, GNU General Public License, y de licencias Creative Commons, así como c) las propuestas y estrategias colaborativas 
por el Conocimiento libre, tales como las desarrolladoas por la Open Knowledge Foundation o por Science Commons, entre otras a destacar.

Aún cuando nuestro abordaje parte de un enfoque global, focalizamos nuestra investigación en aquellas plataformas y proyectos de crowdsourcing y de crowdfunding cinematográfico surgidos en el ámbito español a lo largo del quinquenio 20072011, premiando a su vez el estudio de aquellos casos en los cuales redes sociales y herramientas de acceso libre han tenido un papel determinante para el éxito y/o eco de estas iniciativas de producción cinematográfica eminentemente colaborativa.

\section{La cultura libre en las industrias creativas}

Inspirado por el artículo 'The Cathedral and the Bazaar'(1999), de Eric S. Raymond, Jeff Howe enunció por primera vez y desarrolló el concepto crowdsourcing tomando como ejemplo una web que se dedicaba a alojar imágenes que los usuarios proporcionaban a cambio de una pequeña compensación económica a los autores para luego revender esas imágenes a los usuarios que las necesitaran: "Crowdsourcing es el acto de tomar una tarea desarrollada tradicionalmente por un agente designado previamente, y externalizarla a, generalmente, un gran grupo de personas como si fuera una convocatoria abierta (...) implica la aplicación de los principios del software de código abierto fuera ese ámbito" (Howe, 2006).

Aún cuando el artículo inspirador de Raymond (1999) giraba en torno al desarrollo de programas informáticos, el contenido de éste permite ser exportado al ámbito de la producción cultural en general. En su obra previa, Raymond identificaba a las grandes empresas de programación informática con la construcción de catedrales, con sus trabajadores "encerrados a piedra y lodo, sin sacar al mercado versiones de prueba" (Raymond, 1999: 27). Frente a este modelo, Raymond opone el trabajo en las comunidades propias del software libre, en el que los desarrolladores llevan a cabo su trabajo como si de un bazar se tratase, "colmado de individuos con propósitos y enfoques distintos de donde surgirá un sistema estable y coherente" (Raymond, 1999: 31).

La dinámica propia del bazar facilita y promueve la diversidad de ideas y la solución de un problema desde distintas perspectivas, lo que da más riqueza al proyecto final, en opinión tanto de Raymond como de Howe. Y si en lugar de un pequeño grupo de personas tenemos un gran grupo de colaboradores -no necesariamente situados en un mismo lugar- conseguiremos un trabajo mucho más depurado cumpliéndose el dicho "cuatro ojos -en este caso millones de ojos- ven más que dos".

$\mathrm{Al}$ frente de este gran grupo de colaboradores tiene que haber además un coordinador con don de gentes y capacidad de comunicación que sea capaz de reconocer las buenas ideas ya que, según Howe, "cada individuo posee algún conocimiento o talento que algún otro individuo lo encontrará valioso" (Howe, 2006). Aunque sea un trabajo hecho por muchos es necesaria una persona que coordine a todos los parti- 
cipantes para que el bazar no se convierta en un caos de opiniones desordenadas sin un objetivo fijo. Éste director de orquesta será el encargado de organizar el trabajo y orientar a todos los participantes a un fin común, evitando que cada uno aporte sus ideas indiscriminadamente, sin atender a un objetivo concreto.

Y lo último y más importante si queremos que un proyecto de tipo crowdsourcing tenga éxito en opinión del propio Howe: debemos tener un medio decomunicación que conecte a todos los trabajadores sin importar su ubicación física. Esto es, Internet.

Aunque estos tres elementos -un gran grupo de colaboradores, un coordinador y un medio para estar interconectados- pueden parecer suficientes para desarrollar un proyecto de tipo crowdsourcing, no podemos olvidarnos de la parte final de la caracterización que hemos apuntado antes de Howe, más propiamente un lema: "aplicar los principios del software de código abierto fuera de ese ámbito" (Howe, 2006).

De acuerdo con ello, un proyecto audiovisual de tipo crowdsourcing deberá seguir los principios del código abierto (que quedan fijados por el decálogo de requisitos que para tal escritura de programas establece la propia Open Source Iniciative), y que aplicados al desarrollo de estrategias y proyectos de producción audiovisual de tipo crowdsourcing exigirá a éstos seguir y cumplir los siguientes cuatro principios-guía: (1) Transparencia: usuarios y participantes deben estar informados del transcurso del proyecto, sin que se les escondan los avances, éxitos o fracasos que vayan ocurriendo; (2) Participación: hay que permitir a la comunidad participar en el proyecto ya sea aportando ideas, interviniendo en el proceso de trabajo o incluso aportando recursos económicos; (3) Colaboración: más allá de la mera participación individuo a individuo, hay que escuchar el resto de voces implicadas e intentar colaborar al máximo que podamos con éstas; (y 4) Libertad: es necesario que el resultado de nuestro trabajo se distribuya y llegue al mayor número de manos posibles. Todo el material empleado para llevar a cabo el proyecto, pongamos u largometraje original, tiene que ponerse a disposición de los usuarios con total libertad para que puedan manipularlo e incluso -por ejemplo- rehacer la película a su antojo.

Estos cuatro principios-guía encontraron sin duda su traducción performativa en un conjunto significativo de proyectos informáticos de las últimas décadas, pero también desde el año 2006 y hasta la actualidad en un conjunto de proyectos audiovisuales afines emergentes de plena significación en la escena internacional reciente.

\section{Producción colaborativa de proyectos cinematográficos}

La cultura colaborativa en el ámbito de la creación y la producción audiovisual contemporánea no se ha limitado a operar con la capacidad de trabajo de los individuos, sino que ha dado lugar también a vías de colaboración económica, favoreciendo que los colectivos que implementan estrategias productivas de tipo crowdsourcing puedan llegar a sustituir -cuando menos a complementar- las cuatro vías tradicionales para la financiación de una producción audiovisual, esto es: (1) la financiación directa 
por parte del productor, (2) la financiación indirecta, sea mediante la capitalización de sueldos, mediante la participación en beneficios, o mediante pagos diferidos, (3) La financiación comercial a través de estrategias tipo product placement, o bien a través de merchandising, y (4) la financiación pública mediante subvenciones que proporcione alguna de las diversas entidades u organismos públicos (Fernández \& Barco, 2010).

Aunque estas cuatro vías de financiación siguen siendo las predominantes y hegemónicas en la actualidad, éstas no resultan accesibles a muchos creadores audiovisuales, que lógicamente se ven abocados a otras vías alternativas de financiación. Abrirse paso en el mercado audiovisual es difícil, y conseguir financiación es cada vez más complicado si no se tiene un cierto renombre establecido en el sector audiovisual. De nada sirve una buena idea, un buen guión, buenas cualidades o un buen equipo técnico si no se dispone del dinero suficiente para completar satisfactoriamente la producción proyectada. Es aquí donde entra juego Internet y con él la financiación y colaboración en masa, o crowdfunding.

El crowdfunding se ha convertido en una opción clave para aquellos emprendedores audiovisuales sin suficientes recursos para llevar a cabo su proyecto. Y no son sólo creadores individuales su target natural, también productoras audiovisuales de tamaño medio y pequeño como -entre otras- las europeas BlindSpot Pictures o 27 films han sacado provecho de éste elaborando un modelo mixto de financiación que les ha permitido seguir adelante en tiempos recientes.

Aunque el crowdfunding considerado habitualmente como una actividad para obtener ingresos para nuevos proyectos y negocios solicitando microdonaciones por parte de un gran número de interesados, éste se ha llevado a cabo desde hace muchos años, antes de que Internet, e incluso la televisión llegara a nuestras casas, tal y como testimonian en el ámbito español los tan conocidos maratones que se llevaban a cabo en la radio - y actualmente en televisión - con el fin de recaudar dinero del público para ayudar a diversas organizaciones humanitarias.

En la ideología subyacente a las iniciativas de tipo crowdfunding se insiste además que a cambio de su aportación, el colaborador -o inversor- reciba a su vez a cambio algún tipo de contraprestación -no necesariamente económica. En ocasiones, por ejemplo, aparecer en los créditos es un incentivo suficiente para que otros colaboren. En este sentido, una de las recomendaciones habituales para emprender un proyecto financiado en masa es tener una comunidad previa interesada en lo que vamos a hacer, tal y como ilustra el proyecto publicado en la plataforma KickStarter, Double Fine Adventure, un videojuego sin siquiera título definitivo, que consiguió reunir el año 2012 los $400.000 \$$ necesarios en tan solo 8 horas y alcanzando más de tres millones de dólares de alrededor de 87.000 inversores. 


\section{Plataformas y proyectos de crowdsourcing y crowdfunding en la producción cinematográfica española (2007-2011).}

Con el fin de ahondar en la caracterización de las implicaciones que estas nuevas vías emergentes de financiación y producción audiovisual -de naturaleza eminentemente colaborativa- propias de la sociedad red tienen para las industrias creativas y para el conjunto de la acción comunicativa contemporánea, a continuación analizamos una selección de plataformas y proyectos cinematográficos pioneros en el ámbito español en el quinquenio (2007-2011).

En ellas, como veremos, entran en acción a) lo tres constituyentes que hemos señalado con anterioridad - un gran grupo de colaboradores, un coordinador y un medio de comunicación para estar interconectados-, b) la inspiración por los principios del código abierto en los ámbitos audiovisual y/o multimedia, y finalmente c) el desarrollo de estrategias -exclusivas y/o complementarias- de financiación en masa, resultando de ello tanto su ejemplaridad y originalidad, como su interés para una caracterización adecuada de los modos emergentes de producción audiovisual en la era digital.

\subsection{Plataformas.}

La emergencia de Partizipa -primera web y plataforma de crowdfunding que aparece en España- marca el inicio de esta vía de financiación en la producción cultural hispana a partir del año 2007, hasta convertirse en la actualidad en un recurso utilizado habitualmente por jóvenes creativos que pueden así intentar llevar a cabo su proyecto al margen y/o de forma complementaria a las vías de financiación tradicional.

Tras Partizipa, otras plataformas de crowdfunding surgidas en el quinquenio posterior 2007-2011 destacan tanto por su nivel de implementación, como por el eco específico alcanzado en el sector audiovisual. Así, Lánzanos aparece en 2010, destinada a todo tipo de proyectos (audiovisuales, científicos, literarios...). Sus normas de funcionamiento prescriben que cuando un proyecto es presentado por uno de los miembros de la plataforma, éste sea analizado previamente para ver si cumple unos requisitos mínimos prefijados con anterioridad en cuanto a presentación y contenidos. Sólo una vez superado este filtro será colocado en 'La Caja', esto es, un espacio público en el que el proyecto propuesto tendrá que recibir al menos cien votos antes de ser publicado definitivamente. Finalizado el plazo de recaudación, si el proyecto ha superado su objetivo el autor recibe el dinero para llevarlo a cabo.

Goteo, una plataforma de crowdfunding gestionada por la Fundación Fuentes Abiertas desde el año 2011, tiene también como las dos anteriores un foco amplio de acción destinado a financiar proyectos de carácter tanto social, como cultural, científico, educativo, tecnológico o ecológico, aunque con la peculiaridad de que los proyectos presentados tengan un ADN abierto común, es que deben cumplir la filosofia del software libre beneficiando al mayor número de personas. Goteo esta- 
blece asimismo cuatro vías diferentes de aportación a los proyectos en concurrencia: ingresos individuales, retornos colectivos, capital riesgo y colaboración distribuida.

Con Verkami, que tuvo sus primeros pasos en 2009, accedemos ya a la implementación de una plataforma de crowdfunding para proyectos específicamente creativos en ámbitos como el cine, la música, el teatro, el cómic, o la fotografía, y con más limitaciones que las plataformas reseñadas anteriormente: un autor sólo podrá tener un proyecto simultáneamente publicado y deberá superar unos objetivos mínimos establecidos por la propia plataforma. Si en el periodo preestablecido (habitualmente de 40 días) para conseguir la financiación se consigue el objetivo económico indicado, éste se ingresa al creador del proyecto.

Finalmente destacamos Kifund, plataforma lanzada en 2011, de especial interés en el marco de investigación que hemos establecido, porque merece ser reconocida como la primera plataforma de crowdfunding en España y en el conjunto de países de habla hispana especializada únicamente en proyectos audiovisuales, proporcionando financiación para cortometrajes y largometrajes de cualquier género, series Web y $\mathrm{TV}$, videoclips, festivales y muestras de cine, desarrollo de nuevas plataformas de distribución, e incluso publicaciones relacionadas con el cine. Siguiendo la filosofía de las plataformas anteriores, los inversores pueden recibir recompensas de todo tipo, desde material promocional a formar parte del equipo inversor y recibir un porcentaje de los beneficios. Todo proyecto publicado y promocionado en su interior debe alcanzar unos objetivos mínimos establecidos por la propia plataforma. Si en el periodo preestablecido para conseguir la financiación se consigue el objetivo económico indicado, éste se ingresa al responsable original del proyecto.

\subsection{Proyectos.}

La emergencia de estas y otras plataformas de crowdfunding coincide en el mismo periodo analizado (2007-2011) coincide con el desarrollo de proyectos de crowdsourcing cinematográfico pioneros en el ámbito español, desarrollados todos ellos desde un mismo espíritu comunitario y colaborativo en red, y financiados o cofinanciados en masa. De entre todos ellos, destacamos tanto por el nivel de implementación alcanzado, como por el eco obtenido los casos de El cosmonauta, La wikipeli o La tweetpeli.

El cosmonauta (2009-2011) tuvo su origen en una iniciativa del director Nicolás Alcalá coproducida por los estudios Riot Cinema Collective, que obtuvo una gran repercusión, alcanzando un eco significativo en numerosos medios de comunicación generalistas, en festivales internacionales y desarrollado iniciativas tan interesantes como la presentación de un concurso de diferentes remezclas a partir de las imágenes del tráiler de la película. Aunque dispuso de financiación privada, así como de ayudas públicas, ambas vías de financiación tradicional se vieron significativamente complementadas por las aportaciones de usuarios y miembros de la comunidad generada durante su proceso de producción en la red, que pudieron participar directamente en el proyecto haciendo aportes desde $2 €$, y recibiendo a cambio un Welcome Pack con 
diferente material promocional, un certificado de productor y la garantía de aparición posterior en los créditos del largometraje.

La wikipeli (2009-2010) es un proyecto que aunó el patrocinio de la empresa cervecera nacional Mahou y la colaboración a través de la red, en el que las decisiones de los internautas eran vitales para la evolución de la producción y realización de dos cortometrajes publicitarios originales. En 2009 se estrenó la primera edición de La wikipeli: Universos. Las cifras de participación alcanzadas dan cuenta del grado colaborativo alcanzado en su co-creación: un total de 3.257 internautas participaron como co-directores, 686 nombres para el protagonista, 217 posibles títulos, 114 castings para algunos de los papeles, 112 canciones para la banda sonora y cerca de 100 imágenes de localizaciones. El cortometraje, de 23 minutos de duración fue dirigido por José Corbacho y Juan Cruz, y durante cuatro meses los internautas decidieron componentes del guión, el atrezzo, los actores e incluso del rodaje de la película. El año siguiente se llevó a cabo la segunda convocatoria, esta vez dirigida por Jaume Balagueró. Éste propuso una breve sinopsis a partir de la cual se desarrollaría el resto de la historia. Los participantes en esta convocatoria casi se duplicaron y se siguió un patrón similar a la primera edición en la que a partir de convocatorias abiertas los internautas decidían mediante votación diversos aspectos del cortometraje incluidos el cartel de la película y el tráiler. En este segundo cortometraje se empezó a su vez a hacer uso de Facebook y de algunos de sus herramientas para difundir el proyecto u organizar el trabajo.

La tweetpeli (2010-2011), el tercero de los proyectos cinematográficos que destacamos resulta pionero en el ámbito de lengua española por hacer uso única y exclusivamente de las redes sociales -en este caso Twitter- para desarrollar un proyecto cinematográfico de modo colaborativo. Este proyecto no partía de ninguna sinopsis previa, sino que absolutamente todo era elegido por los usuarios de Twitter que desearan participar. La idea original provino de Valentí Sanjuan, presentador del programa de radio Vist i no vist de Catalunya Ràdio a sus oyentes. Tras ello, se crearon varios equipos con un coordinador a los que los participantes se podían apuntar (comunicación, producción, patrocinio, guión, fotografía, diseñadores y programadores) con el fin de organizar el trabajo colectivo, e intentando democratizar la toma de decisiones en torno a la producción y a la realización del proyecto. Así, por ejemplo, para el guión, se recibieron 429 historias de las que se eligieron 20 y se reestructuraron para hacer una película en la que 10 historias se irían cruzando formando parte de un todo y cada una dirigida por una persona distinta. Iguamente, más de medio centenar de diseñadores participaron en la elaboración de carteles, dossiers de prensa, chapas, invitaciones, así como de un website promocional. También músicos, compositores o cantantes fueron invitados a participar.

Aunque el proyecto finalmente no se completó más allá de la fase de preproducción, constituyó sin duda una de las iniciativas pioneras más destacadas del periodo fundacional analizado, en especial en su acentuación del papel jugado por las redes sociales en su ideación y proceso de trabajo colaborativo posterior. 


\section{Conclusiones}

1) El concepto de crowdsourcing tiene su base en el movimiento del software libre y en la cultura de código abierto precedentes, que establecen las bases conceptuales y performativas de un amplio abanico de iniciativas creativas afines posteriores desarrolladas en los sectores culturales más diversos. En afinidad con ello, las iniciativas de tipo crowdsourcing se conforman a partir de a) la existencia de un gran grupo de colaboradores, b) un coordinador y c) un medio de comunicación para estar interconectados, así como desde una necesaria concepción comunitaria de los bienes culturales en la sociedad red.

2) La emergencia de plataformas de crowdfunding en España el periodo analizado es una muestra significativa de la ampliación más allá del campo informático de los valores inspiradores del movimiento del software libre y de la cultura de código abierto. En el campo específico de la producción audiovisual más reciente, éstas plataformas se constituyen en una vía revolucionaria de financiación más allá de las vías tradicionales, convirtiéndose tanto en una opción para emprendedores audiovisuales sin suficientes recursos para llevar a cabo su proyecto audiovisual, como en una vía pionera que exprime las posibilidades comunicativas que ofrecen Internet y las redes sociales para la producción cinematográfica.

3) Tras la irrupción en el bienio 2005-2006 de experiencias y proyectos significativos pioneros en el escenario internacional de crowdsourcing audiovisual, el quinquenio posterior 2007-2011 testimonia la emergencia de iniciativas pioneras similares en el escenario de la producción cinematográfica española, tales como las plataformas Partizipa, Lanzanos, Goteo, Verkami y Kifund, o los proyectos El cosmonauta, La wikipeli, o La tweetpeli.

4) Las plataformas de crowdfunding y los proyectos cinematográficos colaborativos hispanos referenciados se han desarrollado de forma sinérgica a lo largo del periodo 2007-2011, inaugurando tanto nuevas vías para la creación y producción audiovisual colaborativa en y desde la red, como nuevas opciones de financiación en masa alternativas a las existentes tradicionalmente en la industria cinematográfica española previa.

\section{Referencias bibliográficas}

ALBERICH, J. \& ROIG, A. (2008). "Creación y producción audiovisual colaborativa. Implicaciones sociales y culturales del uso de software libre y recursos audiovisuales de código abierto". En: UOC Papers. Revista sobre la sociedad del conocimiento, $\mathrm{n}^{\mathrm{o}}$ 7, Barcelona: FUOC. http://www.uoc.edu/uocpapers/7/dt/esp/ alberich_roig.html [17-08-2013].

ALBERIC $\bar{H}$, J. \& ROIG, A. (2010). "Creación colectiva audiovisual y cultura colaborativa on-line". En: Icono14. Revista de comunicación audiovisual y nuevas 
tecnologías, vol. 15, Madrid: UCM. http://www.icono14.net/ojs/index.php/ icono14/article/view/282/159 [10-11-2012].

CASACUBERTA, D. (2003). Creación colectiva. En Internet el público es el creador. Barcelona: Editorial Gedisa.

CHRISTOPHERSON, S. (2008). "Beyond the self expressive creative worker. An industry perspective on entertaiment media". En: Theory, Culture \& Society, vol. 25, n. 7-8, London: Sage. p. 89-112.

ESTELLÉS AROLAS, E.; LADRÓN DE GUEVARA, F. (2012). "Towards an integrated crowdsourcing definition". En: Journal of Information Science, vol. 38, $\mathrm{n}^{\circ}$ 2. California: Sage. p. 189-200.

FERNÁNDEZ, F.; BARCO, C. (2010). Producción cinematográfica: del proyecto al producto. Madrid: Editorial Díaz de Santos.

HARTLEY, J.; MALDEN, M. A. (2005). Creative industries. Oxford: Blackwell.

HARTLEY, J. (2008). "From the Consciousness Industry to Creative Industries: Consumer-created content, social network markets and the growth of knowledge". En: HOLT, J.; PERREN, A. (2008). Media Industries: History, Theory and Methods. Oxford: Blackwell.

HESMONDHALGH, D. (2008). "Cultural and Creative Industries". En: BENNETT, T.; FROW, J. (2008). The Sage Handbook of Cultural Analysis. London: Sage.

HOWE, J. (2006). "The Rise of Crowdsourcing". En: WIRED Magazine, Issue 14.06, June 2006, New York: Condé Nast Publications. http://www.wired.com/wired/ archive/14.06/crowds.html [01-09-2013].

HIMANEN, P. (2001). The Hacker Ethic: And the Spirit of the Information Age. New York: Random House.

JENKINS, H. (2003). "Quentin Tarantino's Star Wars? Digital Cinema, Media Convergence and Participatory Culture". En: THORBURN, D.; JENKINS, H. (2003). Rethinking Media Change. Cambridge. MIT Press. p. 135-172.

JENKINS, H. (2006). Convergence Culture: Where Old and New Media Collide. New York: New York University Press.

LESSIG, L. (2004). Free culture. New York: Penguin Press. (2008). Remix: Making Art and Commerce Thrive in the Hybrid Economy. New York: Penguin Press.

MARTÍNEZ GARCÍA, M.A. (2012). "La estrategia 360 grados como futuro posible para la creación de contenidos. El caso de Jelly Jam". En: Revista Comunicación, $\mathrm{n}^{\circ} 10$, vol.1. http://www.revistacomunicacion.org/pdf/n10/mesa1/014.La_estrategia_360_grados_como_futuro_posible_para_la_creacion_de_contenīdos.El caso de Jelly Jamm.pdf [12-01-2013].

RAYMONDD, E. S. (1999). The Cathedral \& the Bazaar: Musings on Linux and Open Source by an Accidental Revolutionary. New York : O'Reilly.

ROIG, A.; SÁNCHEZ-NAVARRO, J.; LEIBOVITZ, T. (2012). “¡Esta película la hacemos entre todos! Crowdsourcing y crowdfunding como prácticas colaborativas en la producción audiovisual contemporánea”. En: Icono14. Revista de Comunicación audiovisual y nuevas tecnologías, vol. 10, Madrid: UCM. http:// www.icono14.net/ojs/index.php/icono14/article/view/113/79 [12-01-2013]. 
STALLMAN, R. S. (2002). Free Software, Free Society: Selected Essays of Richard M. Stallman. Boston: GNU Press.

XALABARDER, R. (2006). "Les llicències Creative Commons : una alternativa al copyright?". En: UOC Papers, vol.2. Barcelona: Fundació per a la Universitat Oberta de Catalunya. http://www.uoc.edu/uocpapers/2/dt/esp/xalabarder.pdf [01-09-2013]

\section{Los autores}

Francisco David Martínez Gallardo nació en Granada el 9 de Julio de 1987. Es Licenciado en Comunicación audiovisual por la Universidad de Granada (2012), donde obtuvo una Beca de colaboración con el Departamento de Información y Comunicación de la propia Universidad de Granada, y Máster de Cinematografía por la Universidad de Córdoba (2012-2013). Actualmente se encuentra ultimando la inscripción de su Tesis doctoral sobre las vías emergentes de producción cinematográfica en la sociedad red.

Jordi Alberich Pascual (La Bisbal de Falset, Tarragona, 1969), Doctor por la Universidad de Barcelona (1998), es Profesor Titular de Universidad de Comunicación audiovisual y Publicidad en la Facultad de Comunicación y Documentación de la Universidad de Granada. Investigador experto en Estética y Cultura Audiovisual Digital, es miembro del laboratorio de investigación SECABA, e investigador colaborador del grupo de investigación SCI2S (Soft Computing and Intelligent Information Systems) y del Internet interdisciplinary Institute IN3, centro de investigación de excelencia de la Universitat Oberta de Catalunya. 